\title{
O jogo da linguagem em entrevistas na seção Conversa da revista Veja: recursos de (im)polidez com interlocutores distintos
}

Marina de Souza Jacob ${ }^{1}$

\section{Resumo}

A interação pela linguagem é um processo a partir do qual é possivel atingir diferentes objetivos com o uso de determinados recursos discursivos. Neste trabalho, analisaremos como se dá o jogo interativo em duas entrevistas realizadas com artistas distintos, na seção "Conversa" da revista Veja, com o intuito de perceber como perguntas e respostas colaboram não só para a revelação de opiniōes dos interlocutores, mas, principalmente, de aspectos de suas personalidades. Os referenciais teóricos da Análise Conversacional encontrados em Goffman (1980; 2011), Fávero, Andrade e Aquino (1998) nos mostram que, no jogo discursivo, os sujeitos representam papéis sociais e buscam nutrir as impressões que tais papéis suscitam através de uma realidade discursiva. Um ator e um cantor, nas entrevistas, são alvos de perguntas que, ora confirmam, ora põem em questionamento os status de ambos, o que os leva a um posicionamento discursivo para manter a coerência de seus valores e sua representatividade.

Palavras-chave: Entrevista. Interação. Polidez.

${ }^{1}$ Mestre em Educação pela Universidade do Estado de Minas Gerais. 


\section{Introdução}

A língua é a base dos diversos encontros, situações sociais, gêneros textuais, e sua análise possibilita a compreensão do complexo jogo das interações, de como os interlocutores se comportam e como o significado do que dizem pode ir além do meramente literal. Neste artigo, analisaremos duas entrevistas curtas feitas com artistas renomados, sob o enfoque teórico da Análise Conversacional, de acordo com Goffman (1980; 2011), Fávero, Andrade e Aquino (1998), cujos pressupostos estão embasados na ideia da existência de uma arquitetura geral em toda interação verbal, por meio da qual os participantes se compreendem e se respondem conforme um sistema de valores e de procedimentos de conduta que organiza a comunicação. Na Análise Conversacional, postula-se que a autoimagem seja socialmente construída, sendo comum que interlocutores socialmente envolvidos ajam de modo a protegê-la, ainda que inconscientemente. Tal autoimagem, também chamada de face, pode ser atingida, positiva ou negativamente, por estratégias conversacionais. A maneira de perguntar, o conteúdo da pergunta, a maneira de responder, a cultura e as relações de poder são fatores que influenciam na comunicação, desestabilizam, estabilizam ou elevam a imagem social, o status dos interlocutores, cujos atos comunicativos podem sempre revelar suas opiniões e/ou traços de caráter à plateia que os assiste. Nas entrevistas em questão, o objetivo é verificar estratégias discursivas de polidez e impolidez - presentes tanto em perguntas quanto em respostas - que ameaçam ou preservam as faces dos entrevistados (ator e cantor) e como ocorrem as negociações durante as falas.

\section{Interação, entrevista: algumas noções}

A interação pode ser considerada um fenômeno central nas relações humanas de modo geral. Para Bakhtin (2003), é ela a essência da linguagem, a qual apenas se concretizará entre falantes, num dado momento, espaço e com certos conhecimentos/ aptidões compartilhados, a partir dos quais os indivíduos não só se comunicam, mas atuam uns sobre os outros. Como evidencia Brait (1999, p. 193), “a interação não implica somente cumplicidade e solidariedade, mas também um certo tipo de embate, de disputa, na medida em que os interlocutores são parceiros de um jogo: o jogo da linguagem”. Estar em contato, portanto, prevê não apenas simpatia e harmonia, como também antipatia e tensões. 
Segundo ela, a interação é um componente da linguagem, das significações, trazendo em si aspectos socioculturais/discursivos que podem ser descritos, analisados e interpretados (BRAIT, 1999). Analisar as interações, portanto, é uma forma de desvelar intencionalidades, posicionamentos, papéis sociais de indivíduos que se encontram rodeados por regras e condutas sociais. Entre as formas de interação mais corriqueiras, encontramos o diálogo/conversação, dos quais nunca renunciaremos ao longo da vida, conforme Marcuschi (2003). Em nosso trabalho, traremos a análise de uma forma de interação não espontânea, e sim formalizada, previamente preparada, com um tipo de pauta ou roteiro: a entrevista.

Para isso, elencamos caracterizações deste gênero do discurso a partir do referencial de Medina (1986), Fávero, Andrade e Aquino (1998), Brait (1999), Marcuschi (2003), bem como do referencial teórico da Análise da Conversação, a partir de Goffman (1980; 2011), aprofundando as noções referentes às estratégias de polidez/impolidez, preservação da face, elementos da imagem/autoimagem social. Pautamo-nos numa abordagem qualitativa e interpretativa.

A entrevista é um gênero textual com estrutura composicional estável, mas ao mesmo tempo flexível e dinâmica. É um tipo de interação verbal, uma prática cultural comum nas sociedades letradas, principalmente com fins de divulgação em grandes veículos de comunicação. É constituída de dois ou mais interlocutores (entrevistador e entrevistados), cada qual com uma função: o primeiro, mediador e orientador do fio discursivo, abre e fecha as perguntas, introduz novos assuntos; o segundo responde às perguntas feitas. A entrevista parte do princípio da oralidade como fundo interativo para, a posteriori, tornar-se escrita. Sua interpenetração informativa, no âmbito do sistema democrático, funciona como distribuição da informação pela pluralidade de vozes dos sujeitos sociais, quebrando-lhes o isolamento, conforme Medina (1986). Tal autora a categoriza em dois blocos: espetacularização ou aprofundamento. O primeiro bloco se subdivide em perfil pitoresco (retrato caricatural de pessoas do mundo da moda, teatro, esporte), inusitado (revelam-se traços excêntricos do entrevistado) ou de condenação (julga-se aprioristicamente o entrevistado). As entrevistas foco de nossa análise se caracterizam como de espetacularização, por não intencionar o aprofundamento em temas científicos ou de relevância social, vindas de fontes especializadas. Trata-se da seção "Conversa" da revista Veja, que se caracteriza por breves perguntas a pessoas do mundo da moda, esporte, televisão. 
Para Marcuschi (2003), os papéis dos agentes discursivos em interações formais são diferentes se comparados aos de interações informais, assim como suas conversas, marcadas por uma relação de assimetria, de desigualdade, pois cada participante desempenha uma posição diferente e tem maior ou menor autonomia para dizer. Vê-se, muitas vezes, uma maior ou menor atribuição de um dos indivíduos discursivos para iniciar, orientar, ajustar, concluir a interação e coagir o(s) outro(s) participante(s) (MARCUSCHI, 2003). Ainda para ele, as diferenças de condições econômicas, culturais e de poder entre participantes interferem nas construções e apropriações do diálogo. A entrevista poderá também apresentar maior ou menor índice de dialogicidade, com expansão ou limitação das respostas do entrevistado, previstas (ou não) em um simples questionário.

O par pergunta-resposta enfoca noções de coerência conversacional e não consiste necessariamente "numa única resposta $(\mathrm{R})$ possível a uma pergunta dada $(\mathrm{P})$, isto é, as possibilidades de preenchimento são várias" (FÁVERO; AQUINO, 1998, p. 123). Ao se atentar para a importância do questionário em formato de perguntas, do contexto e objetivos da conversa, Fávero e Aquino identificam uma organização textual peculiar na entrevista, que se desenvolverá sob uma interação estratégica diferenciada, "com efeitos cumulativos".

[...] isto é, o entrevistador pode formular um pedido de informação, de confirmação ou esclarecimento, ao mesmo tempo em que pode utilizá-la para introduzir, mudar, redirecionar o tópico. Outra possibilidade corresponde, por exemplo, à utilização da pergunta como elemento de manutenção do tópico, aproveitando para mexer com a face do entrevistado (FAVERO; AQUINO, 1998, p. 123).

Esses efeitos cumulativos em que o entrevistador (re)direciona, (des)organiza os tópicos da conversa com suas perguntas, no entanto, não é unidirecionado, mas "bidirecionado" (FÁVERO; AQUINO, 1998), com possibilidades e permissões ao entrevistado e ao entrevistador para atuarem ativamente. Portanto, ambos têm o papel de construtores do contexto interativo, não existindo este apenas sob a liderança do segundo. Ambos podem inspirar novos enunciados, baseando-se tanto no que já fora dito, como no que está por dizer, digamos, "no ar". As autoras analisam detidamente a relevância das perguntas, por considerá-las manobras estratégicas na continuidade, exploração e redirecionamento da entrevista. 
Conforme Fávero e Aquino (1998) e Brait (1999), para aprofundar análises nas entrevistas é necessário levar em conta a situação imediata em que ocorre, o seu contexto, as características dos agentes envolvidos, seus modos de dizer, bem como o público que estará captando a interação. É preciso ter em conta não só o quesito informatividade da entrevista, mas principalmente o quesito organicidade, de modo "a compreender e fazer-se compreender” (BRAIT, 1999, p. 195). Isto significa ir além dos recursos próprios da língua (sintáticos, morfológicos, entoacionais) combinando-os com as normas "sociais, culturais e situacionais, conhecidas e reconhecidas pelos participantes do evento conversacional" (BRAIT, 1999, p. 195).

\section{Noções de face e recursos de (im)polidez}

Como mostrado, a interação verbal não é sinônimo de acordo e harmonia, mas de um conjunto de interesses em constante movimentação, no qual os actantes discursivos são parceiros "no jogo da linguagem” (BRAIT, 1999). Nessa dinâmica, fluem contradições, tensões, disputas e cumplicidades. A fim de conquistar metas conversacionais, evitar contrastes e desacordos discursivos, o locutor deve comportar-se de tal modo que "toque" no interlocutor algum nível de simpatia, consideração, presteza, também consideradas estratégias discursivas de polidez. Se houver o rompimento desta dinâmica adequada, surgem ameaças às faces dos interlocutores.

O conceito de faces provém dos estudos de Erving Goffman (1980), que evidencia a busca dos indivíduos pelo respeito e pela consideração diante de outros, a fim de manter sua vida social e sua imagem. Cada um busca formas diferentes de manter a honra, a boa conduta, e, nem sempre, um indivíduo é capaz de afirmar-se com a mesma notoriedade perante grupos distintos. Sabe-se que a honra foi, durante séculos, conquistada através da violência, da força bruta. No entanto, desde o século passado, com os tratados de direitos humanos e outras legislações, este costume tem diminuído, como nota Goffman (2011). Assim, no mundo atual, as formas de resolução de conflitos, de manutenção do respeito se dão comumente pela "preservação da fachada", ou seja, por um modo de agir socialmente correto. Quando o indivíduo assim procede, merece ser tratado com mérito; ao contrário, quando desliza, pode colocar-se em risco. Goffman (2011, p. 10) pretende "identificar os incontáveis padrões e sequências naturais de comportamento que ocorrem sempre que pessoas entram na presença imediata de outras". O esforço para manter coerente e aceita a 
face ou fachada perante os outros exige mecanismos verbais e não verbais. A polidez é um deles. Recursos de polidez/impolidez são considerados como reguladores da interação e da conservação da face, a qual é definida como um "valor social positivo que uma pessoa reclama para si", isto é, "a imagem do self delineada em termos de atributos sociais aprovados" (GOFFMAN, 1980, p. 77), que variam em cada cultura.

De acordo com Brown e Levinson (1987 apud FÁVERO; ANDRADE; AQUINO, 2000), a face, ou seja, a imagem pública é criada e mantida por todo e qualquer indivíduo, e apenas se erige com ânimos e trabalhos contínuos no meio social. As faces estão divididas em dois blocos: face negativa (consistindo dos territórios temporal, espacial, corporal, mental, envolvendo a liberdade de ação/domínio do próprio território) e face positiva (vontade de ser aceito pelos outros de modo que estes também compartilhem as mesmas vontades). Ao lançarem-se na interação social, que não é harmônica continuamente, as faces dos indivíduos podem correr risco, desestabilizarem-se pelas vulnerabilidades do porvir. A cada encontro, portanto, a estratégia de polidez serve para manter-se a cordialidade e as boas relações, que variam conforme a sociedade em questão. Tanto a cultura quanto a língua desta sociedade influenciam e suscitam tais normas/comportamentos sociais, conforme Fávero, Andrade e Aquino (2000). A impolidez, por sua vez, contrária à polidez, ameaça as faces, pode figurar como seleção estratégica, racional, irônica. Ambos os recursos - de polidez e de impolidez - trabalham juntos e com diversidade para evitar ou causar transtornos às faces dos indivíduos.

Constituem, portanto, importantes ferramentas verificadas neste trabalho, os recursos de polidez/impolidez - também chamados de polidez positiva ou negativa -, que preservam ou ameaçam as faces dos indivíduos. Adentraremos o universo de duas entrevistas curtas na seção "Conversa" da revista Veja. Além de aprofundar a noção de preservação de faces, analisaremos as chaves de pergunta-resposta que (re)direcionam o posicionamento, tanto do entrevistado quanto do entrevistador, gerando efeitos cumulativos e possibilitando múltiplas atuações para ambos, conforme Fávero e Aquino (1998). 


\section{Revista Veja - Seção Conversa}

Selecionamos duas entrevistas cujo intuito jornalístico não se refere ao aprofundamento de conhecimentos relevantes na área científica ou social, mas a "leves" indagações dirigidas a personagens da mídia que são conhecidos pelo público espectador de grandes redes de comunicação aberta. São eles: Stenio Garcia (ator) e Wesley Safadão (cantor). As entrevistas foram transcritas com alguns pequenos trechos recortados.

\section{“OUVI DIZER QUE ESTOU EM BOA FORMA"2}

Veja: No espetáculo O Último lutador, além de lutar, o senhor dança. É bom mesmo nessas atividades?

Stenio Garcia: Tive umas aulinhas de jü-jtsu para essa peça, e, como já fiz caratê, alpinismo, paraquedismo e acrobacia, está sendo fácil para mim. $\mathrm{Na}$ dança também. Há alguns anos pratiquei jazz e meu corpo, ainda firme, traz essa memória. Também aprendi sobre balé porque fui casado duas vezes com bailarinas. (...)

Veja: Aparecer de peito nu, aos 83 anos, no teatro não é para qualquer um. Como o senhor ajuda a genética?

$\boldsymbol{S}$. $\boldsymbol{G}$.: Corro $15 \mathrm{~km}$ ao menos três vezes por semana, faço ioga e pilates e só como comida saudável. $\mathrm{Na}$ minha casa, há cinquenta pés de frutas e cada um é em homenagem a um amigo querido que se foi. (...)

Veja: Pelo jeito, o senhor não para.

S. $\boldsymbol{G}$.: Não. Minhas lembranças são marcadas por movimentos. Há dez anos, na última vez que estive em Mimoso do Sul (ES), onde nasci, organizamos um mutirão para limpeza do rio em que eu nadava na infância, com meu pai.

Veja: Qual foi a melhor e a pior parte de ter tido fotos íntimas suas e da sua mulher vazadas na internet no ano passado?

\footnotetext{
2 Revista Veja. 13 de janeiro de 2015. P. 26 (Por Thais Botelho).
} 
S. $\boldsymbol{G} .:$ O bom está sendo poder lutar para que haja punição, também para esse tipo de crime. O ruim foi a exposição desnecessária. Aquela foto não foi de sacanagem, íamos fazer um trabalho e estávamos analisando se parecíamos bem. Ouvi dizer que estou em boa forma.

A entrevista tem como foco a comemoração da carreira do ator Stenio Garcia e sua forma física aos 80 anos de idade. Exibe-se a fotografia de seu muque forte, o que nos traz elementos confirmativos da proposta da revista. As duas primeiras perguntas referem-se tanto à atuação profissional quanto pessoal. A luta e a dança participam de cenas de seu espetáculo artístico e da vida íntima. O ator aproveita para divulgar outras atividades já praticadas que também exigem esforço físico, concentração e energia, como paraquedismo, alpinismo e balé. É uma maneira de não só informar aspectos íntimos de sua vida, como também projetar a imagem de si perante o público, como uma pessoa que busca aprendizagens múltiplas para incorporar à sua atuação profissional.

$\mathrm{Na}$ segunda pergunta, o ator recebe um elogio sobre sua forma física e é questionado sobre como mantém este "bem" genético. Ele se demonstra engajado com a vida saudável (faz corrida, pilates, alimentação natural) e aproveita para informar outro dado da vida íntima: seus pés de fruta no fundo do quintal, aos quais oferece nomes de amigos. A face positiva do falante é resguardada e reafirmada como indivíduo que preza a vida: cultiva a saúde, natureza, as artes, os amigos.

No terceiro item-pergunta ("o senhor não para"), o ator aproveita para afirmar outro movimento seu, feito dez anos atrás, como ele mesmo diz: organizar um mutirão para limpeza do rio da cidade onde nasceu e nadou na infância. A revelação destes atos de cultivar uma vida saudável, plantar árvores, limpar um rio é uma soma de elementos simbólicos que repercutem na face positiva do ator, influenciando a forma como a sociedade reage diante do mesmo. Contém esta soma simbólica um tipo de nobreza de sentimentos e atitudes admirados socialmente.

Mais uma vez, o entrevistador dirige o discurso com tópicos que favorecem a organização da face positiva de Stenio Garcia, sem invasão ofensiva de sua privacidade. As perguntas, como mostram Fávero e Aquino (1998), dirigem os objetivos conversacionais e o desenvolvimento da interação. Até este tópico, a estratégia de polidez positiva é amplamente explorada, tanto pelo entrevistador, quanto pelo entrevistado, tendo em vista 
o acúmulo de pares de pergunta-resposta que permitem projetar uma imagem positiva, amiga, amorosa do ator.

No último tópico, entretanto, a pergunta se encaminha para captar um episódio desagradável de sua vida: a divulgação de fotos íntimas dele na internet. Nesse instante, a estratégia de polidez negativa é acionada: invade-se a sua privacidade com uma pergunta aparentemente objetiva: "Qual a melhor e a pior parte de ter tido fotos íntimas suas e de sua mulher vazadas na internet, no ano passado?”. Na pergunta, somam-se, ainda, duas possibilidades: "melhor e pior parte". Demonstra-se que, até em situações embaraçosas, há o lado positivo. Nesta pergunta, a presença da esposa de Stenio Garcia também é citada. Como nos mostra Guimarães (2010), a estratégia de polidez negativa “(...) pode ser destinada à própria face, à face do ouvinte e à de outros não envolvidos diretamente na conversação" (GUIMARÃES, 2010, p. 66). Assim, o artista vê a necessidade de resguardar a sua face e também a da esposa, e o faz com competência e humor, afirmativo e esperançoso quanto à punição deste tipo de crime. Justifica que a foto não foi de "sacanagem", mas, sim, para um trabalho futuro, uma espécie de ensaio, o que atesta sua reputação diante dos "bons costumes" da sociedade, da mídia, da família. Ainda que a foto se destinasse a "sacanagem", o ator não precisaria justificá-la, no entanto, aproveitou a oportunidade para criar um jogo agradável e afirmar: "Ouvi dizer que estou em boa forma". Não demonstrando incômodo perante a pergunta meio invasiva, dotada de impolidez, pelo contrário, respondeu-a com polidez, como um questionamento natural. Desta forma, ele apresenta-se ao público com coerência expressiva, procurando manter a representação de seu papel social, que é o de um homem culto, equilibrado, bem-sucedido, não se deixando atingir negativamente pela pergunta. Aliás, faz dela um trampolim para demonstrar seu lado físico-sexual preservado, mesmo com a idade avançada.

Como nos mostram Fávero e Aquino (1998), as perguntas funcionam como um continuum a auxiliar na organização da interação e incidem na maneira de responder do entrevistado. Nessa entrevista, a abertura para a face positiva do ator foi explorada desde o princípio, com perguntas voltadas às suas atividades esportivas, artísticas, profissionais, e ele obteve mais chances de ser admirado e aceito pelo público leitor de Veja. Além disso, um vínculo de confiança e solidariedade se firmou entre entrevistador e entrevistado. Só no fim da entrevista Stenio Garcia é levado a revelar o episódio da vida íntimo-sexual - alvo de fofocas jornalísticas - agindo com humor e leveza, reação esta aplicada desde o início da conversa. 
Concordamos com a ideia de que cada entrevista é “única, particular” (FÁVERO; AQUINO, 1998, p. 126). Mas isto não significa um impedimento nas comparações entre as estratégias de pergunta-resposta e de polidez positiva/negativa utilizadas por entrevistadoentrevistador. Aliás, as comparações são úteis para se verificar a abordagem das conversas, seu conteúdo, direcionamento, objetivos explícitos ou implícitos. As entrevistas podem se dirigir ora para o contrato harmonioso, ora para a disputa e polêmica. Quando se quer bem ao entrevistado e se demonstra respeito, advém a face positiva; quando se pretende expor o indivíduo, distorcê-lo, advém a negativa. Ambas permitirão uma interação mais ou menos amigável, respeitosa, podendo ser mantidas, intensificadas ou perdidas conforme o foco da interação. Para Goffman (1980), é natural, nas interações, que os indivíduos mantenham sua face preservada e ao mesmo tempo preservem e respeitem a face dos outros. Apesar disso, as relações sociais, essencialmente múltiplas e embasadas em valores e crenças, são dotadas também de embates e discordâncias.

Vejamos agora outra entrevista cujas estratégias do entrevistador tendem a expor a face negativa do entrevistado, cujo comportamento revela mecanismos de autodefesa.

\section{ENTRE LUIZ GONZAGA E A DISNEY ${ }^{3}$}

Veja: Luiz Gongaza e Dominguinhos estão se revirando no caixão com seu forró eletrônico?

Wesley Safadão: Não, claro que não. Luiz Gonzaga também inovou. Ele trouxe o triangulo e a zabumba para o forró, que antes era tocado só com sanfona. Sobre Dominguinhos, tive a honra de ouvir da boca dele: "Wesley, menino, você está no caminho certo".

Veja: Mas misturar arrocha, brega e funk com forró não descaracteriza o som original?

W. S.: É uma modernização dele. Nossa banda, Garota Safada, tem trompete, sax, trombone, sanfona e backing vocals. Fazemos um forró mais balançado, que no Nordeste chamamos de pisadinha.

\footnotetext{
${ }^{3}$ Revista Veja. 14 de outubro de 2015. P. 38 (Por Thais Botelho).
} 
Veja: Até um ano atrás você era um ilustre desconhecido no Sul e Sudeste, apesar de sua banda ter catorze anos de existência. O que aconteceu agora?

W. S.: Temos 4,5 milhões de seguidores no Facebook. Além disso, convidamos empresários de outras regiões para ver meus shows no Nordeste e fugimos das letras de forró com sacanagem.

Veja: Qual é o segredo para cobrar por show o mesmo que artistas consagrados?

$\boldsymbol{W}$. S.: Nossa estrutura é tão grande e potente como a deles. Investimos 1 milhão de reais em equipamentos de som e luz e levamos todos eles nas viagens.

Veja: Depois de comprar uma Ferrari e um jatinho, qual será a próxima aquisição de novo-rico?

W. $\boldsymbol{S}$.: Não sou novo-rico. Nem mesmo digo que sou rico. Meu próximo sonho é levar meus irmãos, filhos, minha mulher sobrinhos, as babás e meus pais para a Disney. [...]

Nesse contexto, o cantor Wesley Safadão revela um panorama rápido de sua carreira atual. $\mathrm{Na}$ primeira pergunta, diferentemente do que se percebe na entrevista com Stenio Garcia, o entrevistador inicia: "Luiz Gonzaga e Dominguinhos estão se revirando no caixão com seu forró eletrônico". Aparece, nesse momento inicial da pergunta, uma estratégia de polidez negativa, pois busca-se afirmar uma suposta reação negativa, por parte de ídolos do forró (já falecidos), ao ouvir o som eletrônico de Wesley Safadão. Com tal pergunta, infere-se um suposto grau de desqualificação de seu trabalho, indiretamente lançado por Veja, sob o olhar de Dominguinhos e de Luiz Gonzaga. O cantor minimiza a provocação da pergunta e lança mão de uma estratégia de polidez positiva, ao mostrar que Luiz Gonzaga também inovou ao inserir o triângulo no forró, antes executado apenas com o uso da sanfona. Logo, o forró eletrônico seria uma inovação tanto quanto a do astro Luiz Gonzaga. No final de sua resposta, o cantor popular revela uma previsão do renomado Dominguinhos de que estaria no caminho certo, tentando transmitir com esta postura polida a legitimidade de seu trabalho, bem como evitar possíveis desacordos com o entrevistador. 
O entrevistador insiste, mais uma vez, no tópico-pergunta, remodelando-o, "dandolhe continuidade por não ter sido suficientemente explorado" (FÁVERO; AQUINO, 1998, p. 126) e lança: "Misturar arrocha, brega e funk com forró não descaracteriza o som original?". O artista responde com polidez positiva, demonstrando a modernização de sua banda com o incremento de sax, trompete, backing vocals e não a descaracterização do forró, como supôs Veja. O cantor diz que o seu forró contém elementos que favorecem uma forma de maior "balanço", chamada "pisadinha" no Nordeste, informação esta que caracteriza um aspecto da cultura regional, desconhecida pelo entrevistador. Desta forma, o cantor defende que seu produto cultural é feito a partir de tradições e do gosto nordestino.

No próximo par pergunta-resposta ("Até um ano atrás você era um ilustre desconhecido no Sul e Sudeste, apesar de sua banda ter catorze anos de existência. O que aconteceu agora?’), o cantor justifica seu reconhecimento pelo elevado número de seguidores na rede social Facebook - 4,5 milhões. Tal quantia de fãs revela o potencial da banda, que atrai milhões de pessoas sem precisar, para isto, cultivar músicas com tema de "sacanagem".

No tópico seguinte ("Qual o segredo para cobrar por show o mesmo que artistas consagrados?), o entrevistador não só pretende investigar o segredo do cantor quanto ao alto valor de seu espetáculo, como compará-lo, mais uma vez, a outros profissionais. Wesley defende o valor dos shows pela estrutura potente de luz e som, com a qual gastou mais de um milhão de reais.

Por fim, no tópico seguinte ("Depois de comprar uma Ferrari e um jatinho, qual a sua próxima aquisição de novo-rico?"), constata-se uma pergunta que enfatiza o status socioeconômico conquistado pelo artista nordestino pela posse de bens de alto valor. No entanto, a denominação "novo-rico" parece irônica e polissêmica. "Novo-rico" refere-se a um jovem que se tornou rico, com tenra idade, ou o sujeito mais rico, da moda, uma novidade entre os outros ricos. Isto pode ser percebido pelos blocos de perguntas anteriores, cuja sequência movimenta a face negativa do artista e de sua música modernizada, como: “até um ano atrás você era um ilustre desconhecido". Wesley Safadão responde negando a pergunta e diz não ser rico, nem novo rico, mas que seu desejo é levar toda a família e a babá para a Disney, como se fosse ainda uma criança que se encontra em estado de sonho e imaginação. 


\section{Considerações finais}

Neste trabalho, mostramos a importância de destacar as estratégias de perguntaresposta na organização da interação no gênero entrevista. Evidenciamos a noção de face como algo universal e ao mesmo tempo próprio de cada sociedade, com a finalidade de designar o valor positivo da identidade dos indivíduos. Trabalhamos com os conceitos de polidez e impolidez (polidez positiva/negativa), os quais auxiliam a atingir metas conversacionais, conforme as intencionalidades ou desvios dos interlocutores. As análises desenvolvidas a partir de entrevistas da revista Veja confirmam o repertório estratégico da conversação, com destaque, principalmente, para a escolha das perguntas conectadas às propriedades/identidades dos entrevistados. É possível perceber um tom diferenciado nos pares pergunta-resposta que estruturam as duas entrevistas. Com essa diferenciação, notamos uma entrevista com perfil inusitado e outra com perfil de condenação, para retomar a classificação feita por Medina (1986). Na entrevista de Stenio Garcia, ator da rede Globo, idoso, casado, mostra-se um cidadão preocupado com a própria saúde e com o meio ambiente, satisfeito por comemorar mais um ano de sua carreira. Sua face positiva e seus traços excêntricos são postos em relevância, como é típico na entrevista de perfil inusitado. Na entrevista de Wesley Safadão, cantor nordestino, nota-se o uso de tons interrogativos que parecem negativos e colocam em questionamento a qualidade de seu trabalho e sua posição econômica. O estilo dessa entrevista, por sua vez, está mais próximo da condenação, uma vez que parece julgar antecipadamente o entrevistado.

Assim, as faces dos entrevistados são tocadas por recursos de polidez ou impolidez (polidez positiva ou negativa), com carga amigável ou irônica, implicando em valorização ou desvalorização de sua fala ou de sua identidade, variando os objetivos, conforme os participantes envolvidos no ato interativo. Ainda que o entrevistador seja o mesmo, as estratégias de interação variam e são construídas antes do encontro, tendo por base a imagem ou prestígio social que o indivíduo conquistou na coletividade ou diante do entrevistador. 


\section{Referências}

BAKHTIN, M. Estética da criação verbal. Trad. Paulo Bezerra. São Paulo: Martins Fontes, 2003.

BOTELHO, Thais. Conversa com Wesley Safadão. Revista Veja. Panorama. 14 de outubro de 2015, p. 38.

26.

Conversa com Stenio Garcia. Revista Veja. Panorama. 13 de janeiro de 2015, p.

BRAIT, Beth. O processo interacional. In: PRETI, Dino (Org.). Análise de textos orais. 4 ed. São Paulo: Humanitas, 1999, p. 189-214.

FÁVERO, Leonor Lopes; ANDRADE, Maria Lúcia C. V. O.; AQUINO, Zilda G. de O. Discurso e interação. A reformulação nas entrevistas. Delta: documentação de estudos em Linguística teórica e aplicada. São Paulo, v. 14, 1998, p. 91-103. Disponível em: <http://www.scielo.br/scielo.php?script=sci_arttext\&pid=S0102-44501998000300008>. Acesso em: 6 de Jul. 2018.

Papéis discursivos e estratégias de polidez nas entrevistas de televisão. Veredas: Revista de estudos Linguísticos, v. 4, no 1, Jan./Jun. 2000, p. 67-77. Disponível em: <http://www.ufff.br/revistaveredas/files/2009/12/artigo76.pdf>. Acesso em: 6 de Jul. 2018.

FAVERO, Leonor Lopes; AQUINO, Zilda G. de O. As perguntas na organização das entrevistas. Revista da Anpoll, nº 4, Jan./Jun. 1998, p. 121-135. Disponível em: $<$ https://revistadaanpoll.emnuvens.com.br/revista/article/view/283/296>. Acesso em: 6 de Jul. 2018.

GOFFMAN, Erving. A elaboração da face. Uma análise dos elementos rituais da interação social. In: FIGUEIRA, S. (Org.). Psicanálise e ciências sociais. Rio de Janeiro: Francisco Alves, 1980, p. 76-114.

Ritual de interação: ensaios sobre o comportamento face a face. Trad. Fábio Rodrigues Ribeiro da Silva. Petrópolis: Vozes, 2011.

GUIMARÃES, Silvia Bragatto. Entrevista: um estudo do gênero a partir da construção de face e da polidez. Cadernos do CNLF, v. XIII, no 4, 2009, p. 1839-1854. Disponível em: <http://www.filologia.org.br/xiiicnlf/XIII_CNLF_04/tomo_2/entrevista_um_estudo_do _genero_a_partir_da_construcao_SILVIA.pdf>. Acesso em: 6 de Jul. 2018.

MARCUSCHI, Luiz. A. Análise da conversação. 5 ed. São Paulo: Ática, 2003.

MEDINA, Cremilda Araújo. Entrevista: o diálogo possível. São Paulo: Editora Ática, 1986. 


\begin{abstract}
Interaction is a phenomenon of language that aims to achieve different goals with certain discursive resources. In this work we will analyze how the interactive game takes place in two interviews with distinguished artists, in the "Conversa" section of Veja magazine in order to perceive as a Question-answer, collaborating not only in the revelation of opinion, but mainly in aspects of their personalities. The theoretical references of Conversational Analysis found in Goffman (1980; 2011), Fávero, Andrade and Aquino (1998) show that in the discursive game the subjects represent social roles, they seek to nourish the impressions that such roles arouse through a discursive reality. The singer Wesley Safadão and the actor Stenio Garcia in the interviews are the targets of questions that now confirm, sometimes questioning the status of both, which leads them to a discursive positioning to maintain the coherence of their values and their representativeness.
\end{abstract}

Keywords: Interview. Interaction. Politeness

Recebido em: 31/07/2017.

Aceito em: 04/07/2018. 